\title{
11 EFFICIENCY OF TREATMENT METHODS - EMPHASIZING ORGANIC POLLUTANTS
}

\author{
Lennart Mårtensson', Lennart Mathiasson', Staffan Bergström ${ }^{1,2}$, \\ Britt-Marie Svensson ${ }^{\prime}$, Lars Thörneby ${ }^{2,3}$ and William Hogland \\ ${ }^{\prime}$ School of Engineering, Kristianstad University, Sweden \\ ${ }^{2}$ Department of Analytical Chemistry, Lund University, Sweden \\ ${ }^{3}$ Department of Technology, Kalmar University, Sweden
}

\begin{abstract}
Leachate treatment tests were carried out at the pilot plant in Kristianstad, Sweden. After pretreatment the water was divided into different treatment procedures as chemical oxidation by Fenton's reagent, ozone degradation, bioremediation by the Natrix ${ }^{\mathrm{TM}}$ process, geobed filters. Samples was analysed according to inorganics and summary parameters, toxicity and organic pollutants. Ozone oxidation gave the best result concerning reduction of organic compounds but the best efficient treatment was give by the geobed filters. The paper is also describing the pilot-plant in Siauliai, Lithuania. The advantages with these types of leachate treatment methods are low energy consumption, low consumption of expensive chemicals, limited need of maintenance, and they are still capable offering a sustainable treatment alternative.
\end{abstract}

\section{KEYWORDS}

Leachate treatment; organic pollutants; Fenton's reagent; ozone degradation, bioremidation; geobed filters.

\section{INTRODUCTION}

Since antiquity, humankind has used burial as a method of waste disposal. In recent times, however, there is a growing concern among the public for the environmental impact created by municipal solid waste (MSW) landfills. Open dumping in landfills is the world's most common way for disposal of solid waste. Landfilling is often made with low standards in terms of environmental protection. Landfills are subjected to biological and physical factors in the environment and will undergo change over time that can lead to consequences for the environment including the following effects:

- Ground Water Pollution. Landfill leachate can contain a wide variety of toxic metals and organic compounds: lead, mercury, benzene, and vinyl chloride (a human carcinogen) are just a few common landfill contaminants. Many older landfills are unlined, and even newer liners can leak. There is no way to estimate the size or potential clean-up cost of a leak before it happens, making ground water pollution economically as well as environmentally risky. 
- Air Pollution. The process of decomposition of the waste interred in a landfill, as well as the waste itself can release air pollutants in the form of methane and volatile organic compounds (VOCs). Methane is a greenhouse gas, and landfills are the largest anthropogenic source of methane. Some VOCs released by landfills are known or suspected carcinogens.

- Noise Pollution, Odour Pollution, Blowing Trash, and Visual Pollution. Although these effects may not be a problem for the entire community, they can be a problem for residents near a landfill.

\section{The environment in the Baltic Sea}

Bad environmental conditions of the Baltic Sea region have become a major problem. The emission of nitrogen and phosphorus from agricultural activities to the water has lead to euthrophication (Larsson et al., 1985). Pollution was in earlier days regarded as a local problem. It was limited to the nearby surroundings of the pollutant source. However, there was a growing insight of that the problems could not only be concentrated to the source but also pollutants could be spread over a large area and in some cases this can be globally. Persistent halogen organic compounds can be found in every part of the world, even in remote and uninhabited places like the Artic (Alaee et al., 1999). The presence of polychlorinated biphenyls (PCB) in the environment has in Sweden and other countries resulted in a ban of using these substances. These measures have resulted in a fall in levels found in the environment (Monitor, 1998). However, even though the concentrations has fallen the presence of persistent pollutants such as halogen organic compounds, i.e. PCBs and brominated flame retardants (PBDE), cannot be regarded as being of no significance to human health since there exists large gaps in the understanding their effects. The health risks involved with polychlorinated biphenyls were in earlier days regarded low. The adverse effects from these substances can in some populations of vertebrates lead to feminisation and impaired reproduction capacity among males. These observations can be connected to the fact that some of the persistent organic pollutants concerned have hormone-like effects (Monitor, 1998).

The Baltic Sea has a big drainage area with a large human population. Since the Baltic Sea is connected to World Ocean through small narrow and shallow sounds in the southwest the interchange of fresh water is heavily restricted. This has led to that Baltic Sea has become a major sink, final storage; to persistent organic pollutants that has entered it over the years (Agrell et al., 1999).

\section{Treatment methods}

Several methods for treatment of leachate have been tested in several studies. The processes used have been biological, chemical and physical. There exists some full-scale treatment plants but the number is still very small. Some of the full-scale plants are very complicated involving different stages with combination of microbiological processes and physical and chemical processes. Many of the full-scale plants are relatively simple with only an aerated lagoon. The effects have in most cases been studied by analysing the inorganic compounds. Welander (1998) has in her work concentrated more on the effects of biological treatment methods on persistent organic compounds. The choice of which treatment methods to use is due to the composition of the leachate water that varies from one landfill to another (RVF, 1996). 


\section{Biological methods}

The biological methods can be divided into aerobic processes and anaerobic processes. Aerobic methods have an advantage over anaerobic methods in that they can operate in a wide range of temperatures and effectively reduce the content of ammonia. On the other hand, anaerobic methods can reduce the content of heavy metals by precipitation as carbonates or sulphides (Callander and Barford, 1983). The sulphides involved in this process are being formed under anaerobic conditions under reduction of sulphate. Other advantages compared to aerobic are lower energy consumption since no aeration is needed, and less production of excess sludge. Recycling of leachate back to the landfill is a method that reduces the volume due to evaporation, and decreases the concentration of organic compounds due to anaerobic microbiological processes in the landfill.

\section{Chemical and physical methods}

Several methods using chemical and physical processes have been tested. Activated carbon has been used for adsorption of hydrophobic substances such as aromatic compounds. Precipitation is another method used for removal of phosphorus using substances such as aluminium sulphate, ferrous sulphate or lime. Precipitation processes have some effects towards organic compounds as well.

Reversed osmosis is a method showing good results reducing COD and organic compounds. Reverse osmosis had already been used for leachate treatment for many years in Germany. However, this method has problems in that treatment of leachates by $\mathrm{RO}$ can be very expensive due to the presence of membrane-fouling compounds; andit also produces a retentate (concentrate) that can be difficult and expensive to get rid of.

Other chemical and physical methods are oxidation with Fenton's reagent, ammonia stripping and evaporation.

\section{Other methods}

About 50 landfills in Sweden have some kind of leachate treatment. The dominating system among these 50 is some kind of irrigation system (e.g. energy forest). Salix is one type of energy forest that has been used (Hasselgren, 1999). One of the problems with irrigation system is how to take representative samples. Filtering though a bed of peat or a mixture of peat and coal-ash is another is another methods that showed promising results towards metals as well as organic compounds.

\section{THE "LAQUA"-PROJECT}

The project named "LAQUA" started 1 of January 1999. It ran for three years. It was cofinanced by EU-SWEDBALTCOP- Baltic Sea Co-operation Program. Participants from Sweden were Kristianstad Municipality, Kristianstad Waste Management, Kristianstad University and small and medium sized enterprises. From Lithuania participate Siauliai, Municipality, Siauliai University and small and medium sized enterprises.

The aim of the project was to find and develop ecologically and financially treatment methods for leachate from waste deposits. During the project pilot-scale treatment plants were set up, one in each country. Unlike earlier performed studies the project put the focus on persistent organic pollutants. Development of new analytical and toxic screening methods was performed by Kristianstad University and the department of Analytical Chemistry, Lund 
University. Test of treatment methods involving biological treatment, chemical treatment has been performed in Sweden. Other methods such as soil-plant system and treatment with peat will be tested in Lithuania in a newly built pilot plant.

\section{Evaluation methods is essential}

For accurate evaluation of the treatment methods it is crucial with accurate and precise analytical methods. Only then it is possible to design and construct proper treatment methods. In this project with emphasise on organic pollutants in leachate water the evaluation needs sophisticated analytical chemistry. Thus co-operation was established with the School of Engineering at Kristianstad University and the department of Analytical Chemistry at Lund University. Both departments have access to advanced analytical equipment and have great experience in environmental research. Leachate water from municipal solid waste landfills is a very complicated matrix and contains several hundreds of different chemical substances. In order to facilitate the evaluation process the LAQUA-protocol was established (Bergstrom $e t$ $a l, 2001)$. According to the protocol summary parameters such as for example $\mathrm{pH}$, nitrogen, ammonium and heavy metals were determined. The organic compounds were divided into two fractions and analysed with different methods according to their ability to be solved in water. The organic substances considered were phenolic substances, phthalates, PCBs and brominated flame retardants (PBDE). The toxicity of the leachate water was also tested before and after treatment using a small crustacean (Artemia salina). The organism was exposed to the leachate water and the toxic effect was measured as number of individuals immobilised.

\section{The Pilot Plant}

In the pilot plant figure 1, the raw leachate water is first treated in a pre-treatment step. After the pre-treatment step, the leachate water is divided in to the different treatment procedures, geobed filters, chemical oxidation by Fenton's reagent, ozone degradation and bioremediation.

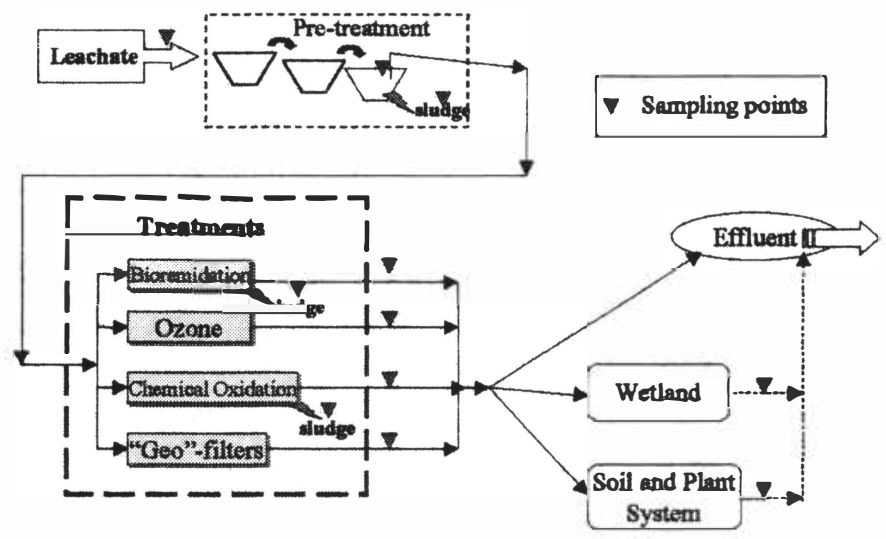

Figure 1. The pilot plant in Kristianstad 
The purpose of the pre-treatment is to aerate the leachate and thus oxidize it and then separate the oxides (e.g. $\mathrm{Fe}_{2} \mathrm{O}_{3}$ ), carbonates and particles by sedimentation.

The chemical oxidation was performed by the principles of Fenton's reagent. The $\mathrm{pH}$ was lowered by sulphuric acid. $\mathrm{Fe}^{2+}$ (in the form of $\mathrm{FeSO}_{4}$ ) and $\mathrm{H}_{2} \mathrm{O}_{2}$ were added. The following reaction forms very reactive hydroxyl radicals $(\cdot \mathrm{OH})$. This gives a very aggressive oxidation, but also some sediment from the formed $\mathrm{Fe}_{2} \mathrm{O}_{3}$. After the treatment the $\mathrm{pH}$ is adjusted to the original level.

The ozone degradation treatment occurred in a reaction tank where ozone $\left(\mathrm{O}_{3}\right)$ and oxygen from an ozone generator were bubbled upstream the down flowing leachate water. The oxidation process is somewhat similar to the chemical oxidation, with an intermediate step, with an aggressive hydroxyl radical.

The bioremediation treatment consisted of an aerated tank with suspended bio film carrier, according to the Natrix ${ }^{\mathrm{TM}}$ process. The bio film carrier is a plastic carrier media, which is kept in suspension and continuous movement by the aeration process. Leachate water is fed to the reactor tank, where the micro organisms growing as a bio film, upon the surfaces of the plastic carrier, decompose organic matter, thus removing $\mathrm{COD}, \mathrm{BOD}$ and toxicity. The $\mathrm{pH}$ is kept stable and $\mathrm{PO}_{4}{ }^{3-}$ is added for the wealth of the micro organisms.

Four different geobed filters were tested. Two of the filters consisted only of peat and two of the filters consisted of peat mixed with carbon containing ash. In one of each type of filters, the water was flowing from top to bottom, and thus, in the other it was pushed from the bottom to the top. The ash and peat filter with water pushed from bottom never worked, due to leaking canvas and thus, data only exist on three filters - GeoU (peat, water under), GeoO (peat, water over) and GeoCO (peat and carbon containing ash, water over).

\section{Sampling and Analysis}

Samples were collected before and after each treatment step, with automated sampling pumps. The pumps pumped intermittent to collection vessels. On a weekly basis the vessels were emptied and samples were taken for the different analyses. In this way a good average of the behaviour of the pilot plant, on a weekly basis, was achieved. For all the treatments, the analysis results were compared relative to the influx into respective treatment.

The samples were analyzed according to the so-called 'LAQUA - protocol', i.e. the samples were divided into three main groups:

Inorganic and

summary parameters: $\mathrm{pH}, \mathrm{Cond}$., $\mathrm{Cl}^{-}, \mathrm{O}_{2}, \mathrm{NH}_{4}{ }^{+}, \mathrm{NO}_{3}{ }^{-}, \mathrm{NO}_{2}{ }^{-}, \mathrm{N}$-tot, $\mathrm{PO}_{4}{ }^{3-}, \mathrm{P}$-tot, As, $\mathrm{Cd}, \mathrm{Cu}, \mathrm{Cr}, \mathrm{Pb}, \mathrm{Zn}, \mathrm{TOC}, \mathrm{BOD}_{7}$

Toxicity:

A new toxicity test were developed and evaluated, with the crustacean Artemia Salina, which tolerate the high concentration of $\mathrm{NaCl}$ in Kristianstad leachate water. The toxicity is measured by $\mathrm{IC}_{50}(\%)$ value, i.e. the amount of leachate water, in $\%$, which gives a $50 \%$ immobility response of the crustaceans. 
Organic pollutants: The organic pollutant samples were further divided into two main groups, polar and more unpolar, to achieve information of the behaviour of pollutants with different physical characteristics. Phenolic compounds were studied using a fully automated analytical system consisting of a supported liquid membrane extraction unit (SLM), connected to an HPLC-DAD equipment. Unpolar pollutants, e.g. polybrominated diphenyl ethers (PBDE), were first extracted from the leachate using solid phase extraction (SPE) to $\mathrm{C}_{18}$ disks, followed by supercritical fluid extraction (SFE) of the disks, and final analysis by GC-ECD.

\section{RESULT AND EXPERIENCES}

Evaluation of the results from the analysis is still in progress. Preliminary results are discussed below. All results were statistically treated, at $95 \%$ confidential level, with twoway ANOVA, with analysis parameter as dependent variable and date and treatment as factors. Outliers were excluded with box and whiskers plots or/and Dixons Q-test. All results are based on relative comparison. For the organic pollutants, we here consider a normalised average of the response for 9 different phenolic compounds analysed by SLM-HPLC-DAD, and a normalised average of the response of 6 different unpolar compounds, analysed by SPE/SFEt- GC-ECD.

\section{Pre-treatment}

The leachate water entering the pre-treatment step was rather clear and had a dark olive-green to grey colour. After aeration it had turned brown and very particularly. The formed sediment consisted of most $\mathrm{CaCO}_{3}$, most likely from the limestone rich Kristianstad area and $\mathrm{Fe}_{2} \mathrm{O}_{3}$ from iron in the waste deposit. The $\mathrm{pH}$ rose from 7,2 to 8,7 compared to the influx and the conductivity were lowered as consequence of the sedimentation. Also the $\mathrm{Cr}$ and $\mathrm{Pb}$ concentration were lower than in the influx, which indicates some co-sedimentation process with $\mathrm{Fe}$. BOD decreases somewhat compared to the raw leachate water. A decrease by $14 \%$ for the phenolic compounds and a decrease by $30 \%$ for the unpolar compounds are noticed. It is likely that some of the unpolar compounds are found in the sediment.

\section{Chemical oxidation by Fenton's reagent}

After the Chemical oxidation the leachate water had a very rusty colour, and was somewhat sparkling. This is shown by the over-saturation of oxygen (over $200 \%$ ). This indicates that the water needs more time in the sedimentation step (in the pilot plant a couple of hours) in a fullscale facility. The conductivity increased due to the addition of ions. The $\mathrm{IC}_{50}$ for Artemia Salina increased slightly. BOD increased while the TOC was unchanged, which might indicate breakdown of some carbon-compounds. $[\mathrm{Zn}]$ and $[\mathrm{Cu}]$ were slightly increased, probably from contaminated $\mathrm{FeSO}_{4}$. The chemical oxidation showed to be very aggressive towards phenolic compounds, and a strong decrease was shown. The same was shown for the unpolar compounds, including PDBE, for which chemical oxidation shows to be most effective.

\section{Ozone degradation}

The leachate water exiting the ozone degradation tank was clear and light yellow with a green tone and the smell was strongly reduced. $\mathrm{O}_{2}$-saturation is naturally increased. The oxidation 
gives increased $\left[\mathrm{NO}_{3}{ }^{-}\right]$and $\mathrm{BOD}$, while TOC is decreased. $[\mathrm{Zn}]$ is increased, $[\mathrm{Pb}]$ is slightly increased and $[\mathrm{Cu}]$ is remarkably increased (this is probably due to contamination from the inside metal walls of the reaction tank). The ozone-treatment gives the best reduction of both phenolic compounds and unpolar compounds, except for PBDE.

\section{Bioremediation by the Natrix ${ }^{\mathrm{TM}}$ process}

Due to upstart problems the bioremediation process only worked at the end of the pilot plant studies, and thus the statistical selection is somewhat limited. $\left.\mathrm{fHH}_{4}^{+}\right]$is strongly reduced and $\left[\mathrm{NO}_{3}{ }^{-}\right]$and $\left[\mathrm{NO}_{2}{ }^{-}\right]$is strongly increased, while Tot- $\mathrm{N}$ is unchanged. This shows that the biological process works, and a nitrification of the leachate water is under process. The toxicity $\mathrm{IC}_{50}$ value is much higher, almost $100 \%$ i.e. very low toxicity for the treated water. $[\mathrm{Cu}],[\mathrm{Cd}]$ and $[\mathrm{Cr}]$ are slightly increased while $[\mathrm{Zn}]$ is strongly increased, probably due to contamination from the reaction tank.

Good decrease is shown for the phenolic compounds as well as for the unpolar compounds, with the exception of hexa-BDE concentration, which increases a factor of three. This might be from contamination from the plastic carrier media.

\section{Geobed filters}

$\left[\mathrm{NH}_{4}^{+}\right]$is reduced for GeoCO and slightly reduced for $\mathrm{GeoO}$ and $\left[\mathrm{NO}_{3}{ }^{-}\right]$, and $\left[\mathrm{NO}_{2}{ }^{-}\right]$are increased for GeoCO. The changes were clearer the later the samples were taken. This indicates biological activity, which continue to increase by time. The toxicity $\mathrm{IC}_{50}$ value was increased for GeoCO. The correlation of the $\left[\mathrm{NH}_{4}^{+}\right]$to the toxicity should be further investigated. $\left[\mathrm{PO}_{4}{ }^{3-}\right]$ increased for GeoU. Tot-P is slightly reduced for $\mathrm{GeoO}$ and GeoCO. BOD and TOC increased for GeoU, probably due to release of substance from the peat. TOC decreases in $\mathrm{GeoCO}$. [As] increases in $\mathrm{GeoCO}$, probably due to the ash, while [ $\mathrm{Cr}$ ] is slightly decreased. $[\mathrm{Pb}]$ and $[\mathrm{Cd}]$ are slightly increased, which seems to arise from the peat. The geobed filters show good reduction of phenolic and unpolar organic compounds, especially the GeoCO. The GeoU has, however, the lowest efficency for the organic compounds. This can be a consequnce of channel formation in the filter material.

\section{DISCUSSION}

The technological treatments, especially the ozone oxidation, gave the best result conceming reduction of organic compounds in our pilot plant. However the most cost efficient treatment seems to be the geobed filters. For the use in a full-scale facility, further investigation and optimisation of similar filters is needed.

It is obvious that there is a need for measures to be taken in order to improve the environment in Baltic Sea. One of the most important measures must be to purify leachate from landfills to before it contaminates the groundwater and downstream surface waters. Old closed down landfills will continue to leach out noxious agents for more than 30 to 50 years after closure. It will therefore be necessary to perform monitoring and to implement reductive measures in local treatment plants during this period.

It is essential for the improvement of the environment of the Baltic Sea area to create contacts between companies in the Baltic region with knowledge of environmental technology. In the long run it is important that Swedish companies take an active part of the design and construction of new local plants for treatment of heavily polluted wastewater from sewage as well as from landfills. The LAQUA project is a good example showing know-how transfer 
from Sweden to the Baltic region in this area. Thus a pilot plant for local treatment of leachate from a solid waste municipal landfill has been constructed in Siauliai, Lithuania using knowledge obtained from pilot plant studies in Kristianstad.

The pilot plant in Siauliai is valuable as a demonstration facility, displaying the possibilities of local treatment of leachate from landfills. It can in the long run be an asset for the whole Baltic region for the future work in the area of environmental technology. It can also give opportunities for local enterprises to test treatment technology under relatively controlled conditions and with aid of competent personal. The pilot-plant in Siauliai is mainly constructed for testing natural based treatment method and as such suitable for the present technical and economical situation in the Baltic countries. Advantages with such methods are low energy consumption, low consumption of expensive chemicals and limited need of maintenance, and still capable of offering a sustainable treatment alternative.

\section{REFERENCES}

1. Agrell, C., Okla, L., Larsson, P., Backe, C. And Wania F. (1999) Evidence of fractionation of polychlorinated biphenyl congeners along the Baltic Sea region. Environmental Science and Technology 33:1149-1156

2. Alaee, M., Luross, J., Sergeant, D.B., Muir, D.C.G., Whittle, D.M. and Solomon, K. (1999) Distribution of polybrominated diphenyl ethers in the Canadian environment. Organohalogen Compounds 40: 347-350.

3. Bergström, S, Mårtensson, L., and Mathiasson, L. 2000. Evaluation of the efficiency, with respect to organic pollutants, of pilot plant for local treatment of leachate water from a solid waste deposit. The $10^{\text {th }}$ symposium on handling of environmental and biological samples in chromatography. April 01-04, 2001 , Mainz, Germany, p.91.

4. Callander, I. J. and Barfors, J.P. (1983) Precipitation, chelation and the availability of metals as nutrients in anaerobic digestion. Meth Biotec Bioeng. 25:1947-1957.

5. Hasselgren, K. (1999), Utilization of sewage sludge in short-rotation energy forestry: a pilot study. Waste Management and Research 17:251-262.

6. Larsson, U, Elmgren, R. And Wulff, F: (1998) Eutrophication and the Baltic Sea: causes and consequences. Ambio 14:9-14.

7. Monitor (1998) Persistent Organic Pollutants - A Swedish View of an International Problem. Swedish Environmental Protection Agency. (ISBN 91-620-1189-8)

8. RVF (1996) Lokal lakvattenbehandling- en vägledning för val av behandlingsmetod lakvaten från kommunala avfallsupplag. Svenska Renhållningsverksföreningen(Swedish Waste Management Association), Report 1996:4 (in swedish)

9. Welander, U. (1998) Characterisation and treatment of municipal landfill leachates. $\mathrm{PhD}$ thesist. Department of Biotechnology, Lund University. 